2.

\title{
Ein alter Unterschied in der Unterbindung des Nabelstrangs,
}

\author{
mitgetheilt von Dr. Wilhelm Stricker,
} pract. Arzte in Frankfurt a. M.

In Petri Laurembergii Bostochiensis Pasicompse nova, id est accurata et curiosa delineatio pulchritudinis (Regiomont. 1672. p. 117) heisst es: Cum ab umbilico pendeat uterus, si umbilicus ab obstetrice arcte fuerit ligatus et largiter tractus, una quoque trahitur versus inferiora os uteri, quo nomine id oportet et angustius reddi et prolongari. Hinc est, quod matronae bonae jubeant pueris relinquere longam umbilici mensuram, ne nimis intro trahatur et abbrevietur mentula, foemellis vero nullam, at eo constrictior fiat et curtior earum suppellex.

$\mathrm{Da}$ solche abergläubische Bräuche of Jahrhunderte lang sich forterben, so entsteht die Frage, ob irgendwo jetzt noch Hebammen den Unterschied machen, bei Mädchen die Nabelschnur näher am Letb zu unterbinden, als bei Knaben?

3.

Uebersicht über alle in Rostock in Jahre 1870 gesehlachteten Schweine.

Vom Universitäts-Mechanicus A. Petri.

\begin{tabular}{|c|c|c|c|c|c|c|c|}
\hline & 1876 & & & $\underset{\text { Schlachthaus. }}{\text { Im }}$ & $\begin{array}{c}\text { Von } \\
\text { Privaten. }\end{array}$ & Zusammen. & $\begin{array}{l}\text { Trichinische } \\
\text { Schweine. }\end{array}$ \\
\hline \multirow[t]{2}{*}{$\begin{array}{l}\text { Januar } \\
\text { Februar : } \\
\text { März : } \\
\text { April : } \\
\text { Mai : } \\
\text { Juni : } \\
\text { Juli : } \\
\text { August } \\
\text { September } \\
\text { October } \\
\text { November } \\
\text { December }\end{array}$} & 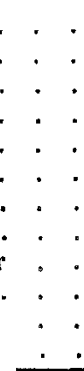 & $\begin{array}{l}\dot{ } \\
\dot{ } \\
\dot{ } \\
\dot{ } \\
\dot{ } \\
\dot{ } \\
\dot{ }\end{array}$ & 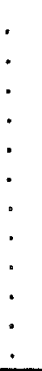 & $\begin{array}{l}649 \\
544 \\
618 \\
557 \\
467 \\
442 \\
347 \\
399 \\
496 \\
654 \\
716 \\
606\end{array}$ & $\begin{array}{r}203 \\
116 \\
30 \\
12 \\
2 \\
4 \\
3 \\
1 \\
6 \\
20 \\
84 \\
189\end{array}$ & $\begin{array}{l}852 \\
660 \\
648 \\
569 \\
469 \\
446 \\
350 \\
400 \\
502 \\
674 \\
800 \\
795\end{array}$ & \\
\hline & & Sum & & 6495 & 670 & 7165 & 0 \\
\hline
\end{tabular}

